\title{
Nonlocality and the Shamanic State of Consciousness
}

\author{
Ede Frecska*, Mihály Hoppál†, Luis E. Luna ${ }^{\ddagger}$
}

ABSTRACT

Healing methods based on the altered states of consciousness common to spiritual or shamanic traditions escape neuroscientific explanations based on classical physics and classical cognition-denoted here as 'perceptualcognitive' (characteristic of the ordinary state of consciousness) information processing. A second foundation of knowledge-named as 'nonlocal-intuitive' approach-with another way for making representation of the environment is recommended to be introduced for better understanding of the shaman's reintegrative role in their community and for an improved interpretation of the shamanic state of consciousness with the 'soul flight' in its center. This essay offers terminology for translating some common elements of indigenous world views into a frame closer to the contemporary Western mindset. The proposed model suggests that when the coping capacity of the 'perceptual-cognitive' mode of processing is exhausted in a stressful or unmanageable situation, or its dominance is eliminated by the use of hallucinogens or contemplation, a frame shift occurs, and an alternate source of environmental information is opened through a 'nonlocal-intuitive' channel. Consequently, the core activity of shamanic practice, the shamanic journey, occurs in a field of quantum connections and is not restricted by space-time constrains, but limited by the uncertainty principle.

Key Words: intuition, nonlocality, shamanic states of consciousness, shamanic journey, spirituality

DOI Number: 10.14704/nq.2016.14.2.934

NeuroQuantology 2016; 2: 155-165

“...practically every scholar forms his own opinion of what constitutes shamanism" (Hultkrantz, 1973, p. 25).

What is Shamanism: Who is a Shaman?

Shamanism represents one of the first spiritual practices of mankind, dating back tens of thousands of years. Only the reverence of the dead, as expressed by archeological evidence of ongoing human care and handling of Homo sapiens skulls over periods of time, or the elaborate reverential arrangement of Neanderthal burial sites, may precede it. ${ }^{2}$ The term 'shaman' originates from the

Corresponding author: Ede Frecska, M.D., Ph.D.

Address: Department of Psychiatry, Faculty of Medicine, University of Debrecen, 4032 Debrecen, Nagyerdei krt. 98., Hungary.

Phone: +36-30-402-6402 Fax: +36-52-255-240

e-mail $\square$ efrecska@hotmail.com

Relevant conflicts of interest/financial disclosures: The authors declare that the research was conducted in the absence of any commercial or financial relationships that could be construed as a potential conflict of interest.

Received: 29 March 2016; Revised: 01 April 2016;

Accepted: 3 April 2016

${ }^{2}$ It is also possible that these spiritual activities had been developed together in parallel.

eISSN 1303-5150
Tungus word of the Evenki people 'saman' referring to "one who is excited or raised." It may also potentially have roots in the Tungus verb meaning "to know." Indeed, in indigenous cultures the word they use for their shaman usually refers to a person who knows or who sees the invisible. At first, the term 'shamanism' was applied by Western anthropologists to the traditional religious practices of the Tungus people, as well as the Samoyeds, Mongols, and Turks of neighboring areas. Later, the term was widely accepted and generalized to refer to any of a group of healers who perform specific functions within their community, and have been called medicine men (or women), witch doctors, sorcerers, wizards, magicians, or seers (Vitebsky, 1995). All of the latter expressions carry certain connotations and are inappropriate to define the group of tribal healers intended as the focus of this essay. 
Most of what we have learned about the ancient, pre-civilizatory practice of shamanism comes from anthropological field studies performed among the tribal people of Central and North Asia, Northern Europe, North, Central, and South America, Africa, Australia and Polynesia (Narby and Huxley, 2001). The cross-cultural commonalities revealed by these studies as to the central role of the shaman within the community, as well as the shaman's practice and worldview, are notably impressive and allow us to make cautious generalizations about this tradition.

Essential to the shamanic cosmology is the concept that the universe has two realms: a "world of things seen" and a "world of things hidden, or unseen." The distinction between the worlds of natural and supernatural is mostly a Western invention, since the shamanic tradition doesn't usually draw such a rigid distinction between them. "For the shaman there is no supernatural world. Only the natural world exists, with its visible and invisible dimensions" (Alberto Villoldo, cited by Ingerman and Wesselman, 2010, p. 3). Beyond this holistic approach there lies a threetiered stratification of the shamanic cosmos: to Lower, Middle, and Upper Worlds. This threetiered cosmological structure is essentially universal, although one can always find exceptions. The "world of things seen" belongs only to the Middle World, which also contains hidden realms, in comparison to the other two tiers, which belong entirely to the unseen domain.

According to Mircea Eliade (1972/1951), a shaman is a man or woman who enters into an ecstatic, altered state of consciousness with the help of rhythmic drumming, rattling, or other type of percussion instrument. In some areas, like South America, psychoactive plants have been used to reach this altered or ecstatic state of consciousness. In the ecstatic state, the shaman journeys to a "non-ordinary" reality, (Castaneda, 1991/1971) to the "world of things hidden," in order to make contact with spirit guides or power animals for accessing personal guidance, empowerment, and healing help in service of the community. The Australian aborigines call this realm of shamanic encounter "Dreamtime." It is also known as "Spirit World" by many indigenous peoples or "Other World" in the Celtic tradition. The shaman is a trained visionary who knows how to enter and navigate this world in a shamanic state of consciousness (SSC) with the help of certain techniques and rituals (Harner, 1990).
An essential part of shamanic rituals is maintaining a monotonous sensory (mostly acoustic, proprioceptive, or occasionally visual) input with the intention of replacing the ordinary, profane sensibility in order to create a nonordinary sensory condition whose rich visual ecstatic trance state experiences open the practitioner's perceptual capacity to the "world of things hidden." The Kalahari !Kung dance for hours while frequently assuming ritualized postures (Goodman, 2003). The Sami people of Lapland use monotonous chanting (joiking), aborigines of Australia play the didgeridoo, and the Bön Po shamans of Central Asia ring bells, all with the same non-ordinary sensory condition in mind (Ingerman and Wesselman, 2010).

A few electroencephalographic (EEG) studies have revealed that shamanic drumming has an acoustic driving effect, in which the rhythm of drumming entrains neuronal firing rates in the low-frequency, high-amplitude Theta range (Jilek, 1982), and low frequency (7 cycles per second) drumming has mind altering effects (Symmons and Morris, 1997). Drumming rhythms in, or close to, the Theta frequency range of 4-7 cps are associated with the trance state (Neher, 1961) and "unusual behavior observed in drum ceremonies is mainly the result of rhythmic drumming which affects the central nervous system" (Neher, 1962, p. 159). It has long been known that auditory driving is a commonly used gateway to the dissociative state (Prince, 1968). Visionary experiences are easily accessed in the theta state, especially if the two hemispheres are in synchronous activity (Frecska et al., 2003). However, it has also been noted (Rouget, 1985) that shamanic rituals don't only rely on monotonous rhythms, but may also produce stimuli that constantly vary. Contrary to acoustic driving, the concept of photic driving by means of light stimulation has a more extensive set of experimental and clinical literature. The phenomenon of active-alert hypnosis is an example of a proprioceptive stimulus induced trance (DeVos et al., 1999). However, achieving the SSC is not only a matter of physiological techniques. Traditional, shamanic cosmology directs and imparts values (as components of the 'set') to all the physical efforts (e.g., drumming, dancing) of the 'setting' intended to break the frame of profane sensibility and facilitate the onset of the SSC, which is not the ultimate goal but the means of contacting spiritual realms during the shamanic healing ceremony. 


\section{The Shamanic Journey: The Soul Flight}

Central to shamanic activity is the shamanic journey, or soul flight, which can be classified as a form of the out-of-body experience. The goal of the shamanic journey is to diagnose and treat illness, to cast spells, to find lost objects, to locate game, to discover hidden enemies, to gain knowledge from animals or plants, or to learn about enemy behavior by remote viewing, divination, or prophecy. For example, a Tungus shaman in Siberia agrees to the request of tribal hunters to locate game during a poor hunting season. Using drumming techniques, he falls into trance to access information which will help his community's hunters (Diószegi, 1998). Men of the Kalahari !Kung tribe leave the settlement for hunting, which may last two days or two weeks. Timely preparation for the return of successful hunters is necessary for processing the game. The people left behind make the appropriate steps long before the hunters' reappearance (Burnham, 2011). A Kamsá shaman in Colombia pursues knowledge about a plant by adding its leaves into the psychoactive beverage yajé, a sacrament indigenous to the Upper Amazon region (Bristol, 1966). The shaman drinks the brew, enters SSC, meets the spirit of the plant, and receives lessons from it. According to shamans using yajé or ayahuasca, the spirit of the plant reveals itself with the help of the plant ingredients, which are widely revered as powerful plant teachers in the Amazon Basin. Through psychopomp work a Hawaiian Kahuna may guide the soul of a departed one to where it is supposed to go after death, according to their belief system (Wesselman, 2011). While the shaman functions in service of the community, his work is not always an altruistic practice; shamans as sorcerers can do harm to others for hire or from selfinterest. ${ }^{3}$ Where there is power, there is always a potential for abusing that power. On the other hand, an authentic and masterful shamanic healer usually has a well-contained dark side (or Shadow in Jungian terminology), but shares several characteristics with the Trickster. Well, the Trickster is not exactly the archetype of the Good Samaritan.

\footnotetext{
${ }^{3}$ Some authors would disagree if sorcerers are a type of shaman. On one hand shamans can do some very wicked things. On the other hand sorcerers can be very benevolent. The main difference is that shamans work on behalf of their community as an obligation. Sorcerers work on behalf of whoever hires them-individuals or groups. But shamans and sorcerers use many of the same technologies; indeed, some sorcerers might be "failed shamans." Knowing the difference in individual cases can be difficult!
} eISSN 1303-5150
According to traditional shamanic lore, the help and information the shaman is looking for is provided by spiritual beings, or deceased ancestors (all non-ordinary entities) from whom the shaman solicits advice, or coerces it by way of trickery or fighting. What separates shamans from trance mediums is that during journeying the shaman retains a certain degree of awareness, maintains control over his or her mental faculties, is fully able to navigate in non-ordinary realms, and, after returning, has a good recollection of the experience. SSC is not an unconscious condition, but a form of focused and expanded consciousness, closer to meditative states, in which the participant intentionally shifts his or her awareness from ordinary perception toward a different "input," which seems to originate from "within," from the inner self occupied by archetypical figures and non-mundane, extraordinary entities. Shamans interact on purpose with these spiritual beings, ask information from them and allow (or force) them to do various things.

With the focused mindfulness of the SSC, shamans manipulate non-ordinary reality in order to elicit changes in the ordinary one (Stevens and Stevens, 2004). They stand with one foot in the "world of things seen" and one foot in the "hidden realm," while communicating between the visible domain of matter and the invisible dominion of spirits. This mediation makes the difference between the role of a shaman and a medicine man or woman. The latter may perform healing rituals based on their extensive knowledge of medicinal herbs, but those activities are limited to the realm of things seen. While almost every shaman is a medicine person to some degree, it is not entirely true the other way around. It is only the shaman's function to encounter divine entities and spirits in order to fulfill therapeutic obligations, and the main work of shamans takes place in the spirit world.

Initiation is an important step of shamanic training which empowers the shaman to become a seer and venture into the mystical world of the things hidden. Archetypical to shamanic healing is the figure of the wounded healer. Inflicting wounds, getting traumatized with the outcome of what is nowadays referred to as 'post-traumatic growth,' is part of the initiation. According to numerous tribal traditions, the bigger the wound is the bigger the healing power becomes. 


\section{The Shaman as Messenger of Reintegrative} Information

In summary, shamans are communicators, carriers of information by which they bring order into the life of their community, and reintegrate it to the environment. Shamanism has four key features: 1) the shaman can enter a specific altered state of consciousness, the so-called SSC, at will; 2) central to this SSC is the shamanic journey to nonordinary realms; and 3) with the help of this journey, shamans acquire some sort of information that they carry over to ordinary reality in service of the community they belong to; 4) moreover, according to Michael Harner (1990), a key element of shamanic practices is contacting a reality which is ordinarily hidden or, to put it differently, interacting with a part of reality inaccessible to ordinary senses. This interaction involves entities, "spirits," and the inhabitants of the non-ordinary realm, which seem to be autonomous beings (in fact quasi-autonomous, as we will discuss later). Spirits and shamans have something in common: both of them can gain access to the other side of reality, and influence it by will, for good or bad purposes.

Shamanic healing is not merely bodily focused, rather it is most commonly healing in the broadest bio-psycho-socio-spiritual sense (Bishop, 2011). Michael Winkelman (2010) emphasizes the traditional healer's role in the reintegrative activity, and coins the term 'psychointegration' as a description of the healing process. Integration, which is reintegration in the case of healing, necessarily means bringing information into the disintegrated system through a process known as divination. "A shaman ... may be able to access information from 'the other side' through enhanced powers of intuition, a practice known as divination" (Ingerman and Wesselman, 2010 , p. 3). Subsequently, we arrive at a new definition of the shaman's mission, which is acting as messenger of divine information in the service of the community. Despite millennia of "field testing," divination has no scientific validation. The ontological status of the non-ordinary realm and its residents is a highly debated issue. While in the world view of indigenous peoples, shamanic encounters and spiritual beings are real (existing "out there"), from an academic stance, they can be interpreted as pathological or wish-fulfilling creations with their room of existence limited to the subjective corners of the mind. "Skeptics favor a view that such practices are basically concerned with nonempirical and ephemeral features, while believers see such spiritual concerns as falling outside of the physical world and the purview of science" (Winkelman, 2010, p. xiii). The discrepancy between these different opinions is usually reduced to the interpretation that the nature of these phenomena depends on the norms of one's own cultural background. This way-with the help of cultural relativism-the ontological aspect is swept away.

In our opinion, this "equality" of opinions degrades the indigenous view. If their interpretation lacks ontological value in scientific thinking, why is there such astonishing cultural similarity in core shamanism across vast geographical areas and eons of time? Migration and diffusion from common ancestors is a weak argument alone, since shamanic practice shows more transcultural commonality than other folkloristic customs have. It is difficult to explain the resilience of shamanic technique while language and social behavior has changed and diverged so profoundly over millennia. Or, if the cross-cultural similarity originates in a combination of the universal makeup of the human mind with a common innate tendency and recurring social forces, then how come that the information originating within subjective recesses of the shamanic healer can work against the entropic deterioration of the community he or she is part of? According to system theory such restructuring influence should originate from the environment outside (and not from the inside). Instead of looking for the psychosocial background of the observed universality, authors turn toward physical foundations for ontological validation, which, as will become apparent, is very close to the interpretation of indigenous belief systems. The view of shamanic practice to be presented here will come closer to the 'emic' view of native people. The term 'emic' refers to how cultural phenomena are understood by members of that culture, as contrasted to 'etic' viewpoints, which are based on rational explanations derived from Western science (Harris, 1979).

In this essay we plan to provide answers to the following questions: How to use contemporary scientific language and metaphors to interpret the two realms of shamanic cosmology: "the world of things hidden" and "the world of things seen?" To what location does the awareness of the shamanic practitioner shift to in SSC? In what realm does the shamanic journey take place in? With whom is the 
shaman interacting? How can shamanic initiation provide the skills necessary to accomplish these feats? And most importantly: What is the source of the reintegrative information?

"Today, many of us who study shamanism feel compelled to describe our art and practice using the language of quantum physics in an attempt to give the shamanic arts more credibility. I believe that doing so actually devalues the 50,000-plus-year tradition of shamanism" (Alberto Villoldo, cited by Ingerman and Wesselman, 2010, p. 3). On this point, we respectfully disagree with this author: translation (if it is a good one) doesn't devalue the original art; if we interpret the universal metaphors of the shamanic cosmos with the metaphors of presentday science then we may develop an intellectual partnership between the two traditions for the benefit of both.

\section{Nonlocal Realism and the Second Foundation of Knowledge}

Here we offer an interpretation of the shamanic journey which implements modern terminology as a replacement for the metaphors of indigenous worldviews. The model was already detailed in an article published in NeuroQuantology (Frecska, 2012a). It is based on the principle of nonlocality and assumes that there are two ways of creating a representation of the environment within a living organism. One is based on the local interactions (energy exchange) mediated by the sensory organs followed by cognitive processing in the neuroaxonal network and serves as the basis of 'perceptual-cognitive'4 knowledge. The other way to have an inside representation of the outside is via nonlocal connections (quantum correlations). This can be the source of another form of knowledge-ignored by Western empiricism and rationalism but well known in contemplative wisdom traditions-termed 'nonlocal-intuitive.' It has been emphasized that the size of the neuroaxonal network makes it ineligible for maintaining this kind of interaction; rather, we should be looking for a subcellular system possibly at the level of the lipoprotein membrane structures-or else (e.g., cytosol) at the bottom of

\footnotetext{
4 'Perceptual-cognitive' in our use strictly refers to a sensory input driven cognitive processing. Visions can be sensed as profoundly perceptual while lacking the activation of the sensory organs (de Araujo et al., 2012). As we will point out later, veridical information accessed during visionary experiences emerges via the "nonlocalintuitive" channel. eISSN 1303-5150

bio-organization-which could function as "quantum array antennae" for nonlocal influences and may serve as some sort of holographic medium for this purpose. The vast majority of cellular connections and even twenty percent of neuroaxonal communication occur through close connections, so-called gap junctions (electrical synapses between neurons). The cytoplasm of neighboring cells is directly connected by microchannels and a subcellular network of the microtubular-microfilamental system passes through the junctions, linking every cell of the body (Peracchia, 2000). The neuroaxonal system of the brain is penetrated and informed by this immense microtubular-microfilamental matrix. While the sensory and accessory cortical areas of the brain are mostly responsible for the perceptual-cognitive representation of the environment, the nonlocal input from the outside world is supposed to be mapped beyond the brain, into the whole body. The characteristics of such a knowledge system is found to be in good accordance with that described by wisdom traditions. Table 1 from the original article summarizes the features of the two foundations of knowledge.

\section{Table 1. Duality and complementarity in knowledge}

\begin{tabular}{|ll|}
\hline $\begin{array}{l}\text { Perceptual-Cognitive } \\
\text { (rational) } \\
\text { hylotropic mode }\end{array}$ & $\begin{array}{l}\text { Nonlocal-Intuitive } \\
\text { (visionary) } \\
\text { holotropic mode }\end{array}$ \\
\hline $\begin{array}{l}\text { learning by observation } \\
\text { from the outside } \\
\text { (objective) }\end{array}$ & $\begin{array}{l}\text { learning by observation } \\
\text { from the inside } \\
\text { (subjective) }\end{array}$ \\
\hline $\begin{array}{l}\text { based on local effects } \\
\text { based on nonlocal } \\
\text { connections } \\
\text { (quantum correlations) }\end{array}$ \\
\hline $\begin{array}{l}\text { neuroaxonal network is } \\
\text { the medium (in the brain) }\end{array}$ & $\begin{array}{l}\text { subcellular matrix is the } \\
\text { medium (in the body) }\end{array}$ \\
\hline electrochemical & quantumphysical \\
\hline operates with symbols & $\begin{array}{l}\text { utilizes holographic } \\
\text { principles } \\
\text { ineffable }\end{array}$ \\
\hline $\begin{array}{l}\text { linguistic } \\
\text { (not necessarily verbal) }\end{array}$ & non-transferable \\
\hline transferable & non-dual \\
\hline splits to subject-object & direct access \\
\hline performs modeling & nebulous, poorly replicable \\
\hline precise, replicable & $\begin{array}{l}\text { the source of contemplative } \\
\text { traditions }\end{array}$ \\
\hline $\begin{array}{l}\text { peaks in the scientific } \\
\text { method }\end{array}$ & \\
\hline
\end{tabular}


Nonlocal correlations are based on entanglement. This crucial issue in our model can be poorly explained by the fact that once, at the moment of the Big Bang, the universe was an entangled system; since entanglement can be lost during further interactions, though evidence of its existence remains in the vacuum state. Perhaps, strangely enough, the role of intentionality may come to the rescue: the intent, the decision of the observer (in our case the shamanic healer) sets up the necessary conditions. This idea may not be considered as far-fetched if one thinks of the "quantum measurement problem", which is the profound enigma of quantum physics! "It [the quantum enigma] tells us that physical reality is created by observation, and it has 'spooky actions' instantaneously influencing events far from each other-without any physical force involved" (Rosenblum and Kuttner, 2011, p. xi). Rosenblum and Kuttner subsequently quote Pascal Jordan, one of the founders of quantum theory: "...observations not only disturb what is to be measured, observations actually produce the measured result" (ibid p. 129). In the same book: "...maybe the same thing, that the observer's choice [one may replace the word with 'decision' or 'intent'] of how to observe affects the prior physical situation." (ibid p. 85). The intimate connection between the observer (subject) and the observed (object) implies the presence of entanglement. 'Signal nonlocality' (Sarfatti, 2005) based on quantum entanglement does not oppose Einstein's theory. Verifiable (i.e., replicable) information exchange requires transfer at luminal speed and occurs within local, though relativistic, space-time boundaries. Without constraints of space-time 'signal nonlocality' provides instantaneous, but nebulous information. Therefore, even the most honest and respectable tribal healer is overshadowed by character features of a trickster in the eye of the rational beholder.

In another work (Frecska, 2012b) it was assumed that nonlocal information about the physical universe offers the missing link between scientific objectivism and subjective experience, including consciousness and spiritual experiences. Based on nonlocal interactions, with the subcellular system as an interface, the body can emulate the Universe. The body may contain the whole cosmos as a quantum hologram. This way the perennial wisdom of "As above, so below (or: As within, so without)," "The kingdom of Heaven is within you," or "Look within, you are the Buddha," gets a perspective closer to the contemporary mindset. The idea that the macrocosm is contained in every microcosm can be found in many other esoteric systems: Tantra, Kabbalah, Sufism, the Gnostic traditions, etc. (Grof, in press). The proposed subcellular matrix can be the mediator of the Jungian 'collective unconscious,' and cytoskeletal quantum holography can explain a very common but obscure phenomenon known as 'intuition.'

Classical cognition, which we called above the 'perceptual-cognitive' mode of information processing, is characteristic of the ordinary state of consciousness and cannot explain all of the peculiarities and the anomalies of the SSC, many of which elude neuroscientific explanation based on classical physics. The introduction of a nonlocality-based intuitive channel is necessary for an ontological interpretation of the integrative altered states of consciousness ${ }^{5}$, such as the shamanic or mystic states.

The 'perceptual-cognitive' foundation of knowledge is a result of the brain's interactions with the local events in the universe. The 'nonlocalintuitive' perception of the world derives from the nonlocal connections of the cosmos. In other words, the local universe of the classical, Newtonian worldview is the reality of our ordinary consciousness, based on 'perceptual-cognitive' processing. On the other hand, the mind's interfacing with the nonlocal aspects of the universe (revealed by modern physics) generates the reality of the non-ordinary states. The supposed dichotomy of the universe (which is ultimately one) corresponds to the indigenous view of the "world of thing seen" and "hidden." Furthermore, as it will be outlined below, the 'nonlocal-intuitive' way is also the source of the subjective component of our consciousness. The main point to be elaborated in the next paragraph is that intuition, consciousness, and nonlocality are interwoven so that the objective and subjective realms are eventually united.

\footnotetext{
${ }^{5}$ An integrative altered state of consciousness may result in complex behavior, creative outcome, healing, and last but not least, it can provide some sort of knowledge (insight, divination, extrasensory perception, or premonition) according to its practitioners. It shouldn't be confused with disintegrative altered states of consciousness such as psychosis, delirium, or drunkenness.
} www.neuroquantology.com 


\section{Emergence of Consciousness during "Learning by Observation from the Inside"}

Ervin Laszlo (2007) stated that "What we call 'matter' is the aspect we apprehend when we look at a person, a plant, or a molecule from the outside; 'mind' is the aspect we obtain when we look at the same thing from the inside." We would add that if we use the 'perceptual-cognitive'-the "learning by observation from the outside" (see Table 1)-then everything is seen as an object without consciousness. Strangely enough, when we use the 'nonlocal-intuitive' method of "learning by observation from the inside"-this is what a shaman uses during soul flight-then everything we encounter is usually conscious. It may depend only on challenging the "entities," appearing in the SSC and their consciousness becomes apparent.

'Nonlocal-intuitive' is a way in which we relate to things from their inside. As Ervin Laszlo pointed out so eloquently, in the eye of the "insider," we always sense the presence of consciousness. This subjective ("insider") observation is common in SSC and universal in tribal traditions. Otherwise who in Heaven (or in the Under World) does one think the shamans are negotiating with and requesting information from? Another example, the Arawaté people of the Amazon, state that in the jaguars' perspective they are the people and we are the jaguars (Viveiros de Castro, 1998). In essence, jaguars are conscious beings and this concept hasn't been learned by "observation from the outside." No one should downplay this indigenous approach unless one can see, touch, or smell his/her own mind. The subjective experience of our own consciousness (phenomenal consciousness) is not based on input from the sensory organs, it is an intuitive knowledge. Here we cautiously hypothesize (since it follows from our idea about the second source of knowledge) that the apperception of our own consciousness (the primal "learning by observation from the inside") also emerges from the 'nonlocal-intuitive' channel. If so, the inner logic of our model requires that the apperception of one's own consciousness have a foundation in nonlocal effects. These effects may result from connecting to a universal source, a connection mediated by information from a holofield beyond space and time (Laszlo, in press). Consequently, intuition, nonlocality, and consciousness seem to be intimately related. Accepting this notion may set a path for unraveling the 'hard problem' of eISSN 1303-5150 consciousness. The eternal philosophical debate over the priority of consciousness or matter seems to us to be transcended by the recognition of the duality of nonlocal and local processes. Consciousness and matter are attributes that depend only on the way we obtain our knowledge.

What follows next is a generalization: the same way we attribute consciousness to ourselves, we can attribute it to everything else via the 'nonlocal-intuitive' approach, since apperception of consciousness seems to be closely related to the intuitive process. The perceptual reality consists of material objects, while the world of intuition is filled with conscious entities. Animals, plants, even rocks, the whole shamanic Cosmos are conscious. They have to be felt that way in a SSC, which has the 'nonlocal-intuitive' approach (the insider's view, the first person's perspective applied to the whole world) as its modus operandi. ${ }^{6}$

\section{Shamanic Trance as a Result of Detachment from Sensory Inputs}

"We must close our eyes and invoke a new manner of seeing... a wakefulness that is the birthright of us all, though few put it to use." --Plotinus (O'Brien, 1964, p. 42)

In order to better understand many of the tranceinducing techniques of shamanic practitioners one must realize the main purpose of the 'perceptual-cognitive' processing with its medium (the brain) and with its assigned functional agent, the ego, in the center. The macroscopic local effects feeding the sensory organs with stimuli are much less limited by the Heisenberg uncertainty principle than the quantum correlations based nonlocal inputs. Therefore, the former can better serve the goal of survival, which needs reliable and predictable stimulus-response reactions, leading to the evolution of the brain as a sort of coping mechanism organ in service of survival. Nonlocal effects can also support that goal by providing "hints" for the locality and certainty based mechanisms, which need to be verified and can be incorporated into the problem solving of the organism. The duality in visual perception presents us a parallel for illustration (Table 2). The foveal vision (belonging to the ventral

6 "What is it like to be a bat?"-Thomas Nagel's (1974) infamous question is not puzzling at all to a shamanic healer.

www.neuroquantology.com 
stream) is limited to tunnel vision without the peripheral input "tips" of the retina (dorsal stream), regardless how rich the fovea is in rods and cones compared to other parts of the retina. ${ }^{7}$

\begin{tabular}{|c|c|}
\hline $\begin{array}{l}\text { Ventral stream } \\
\text { "what or who" channel }\end{array}$ & $\begin{array}{l}\text { Dorsal stream } \\
\text { "where and how" channel }\end{array}$ \\
\hline related to foveal vision & related to peripheral vision \\
\hline involved in apprehension & involved in prehension \\
\hline processes object identification & processes object localization \\
\hline contour-specific mode & locus-specific mode \\
\hline $\begin{array}{l}\text { detail oriented with high } \\
\text { spatial sensitivity }\end{array}$ & $\begin{array}{l}\text { motion oriented with high } \\
\text { temporal sensitivity }\end{array}$ \\
\hline typically high awareness & typically low awareness \\
\hline focal & ambient \\
\hline object-centered reference & viewer-centered reference \\
\hline projects to the temporal lobe & projects to the parietal lobe \\
\hline constructivist approach & ecological approach \\
\hline
\end{tabular}

Apparently shamanic techniques were developed over tens of thousands years for handling crises in the community when the existing routine coping mechanisms were exhausted. Those practices involve methods based on both 'perceptual-cognitive' and 'nonlocal-intuitive' information sources (we refer to them as first and second foundations of knowledge, respectively). The work of a medicine man is based mostly on accrued factual knowledge, while the shaman's endeavor performed during the 'soul flight' belongs entirely to the second means of information collection.

The use of psychedelic drugs, monotonous drumming, repeated refrains of chanting, extreme fatigue, strict fasting, vigorous dancing, and so forth, during shamanic rituals results in the breakdown of the coping mechanisms used in ordinary states of consciousness. The 'coping machinery,' with the ego in its center, may relinquish its dominance in these instances. When the coping capacity of the 'perceptual-cognitive' problem solving is exhausted in a stressful, unmanageable situation, and the brain cannot handle the situation, or its influence is turned off in meditation or eliminated by the use of a powerful psychedelic, a shift occurs. The outcome of this shift is not chaotic behavior, or insanity. A "spiritual universe" with its nonlocal

\footnotetext{
7 This may raise the issue if rational thinking is constrained into some sort of "tunnel vision" without the "irrational" visionary influences. The two are possibly better combined. The Rig Vedas contain good "hints" about the nature of reality discovered by twentieth century physics, yet are unable to advance technological details for making a particle accelerator or a silicon chip. On the other hand, science may benefit from taking some tenets of the wisdom traditions as the focus of its investigation.
} eISSN 1303-5150 influences opens up through the 'nonlocalintuitive' channel while its particular content and form are profoundly affected by the set and setting.

In this state (i.e., SSC) the awareness of the shamanic healer is shifted from the ordinary sensory input toward the nonlocal holographic representation of the environment. The shaman may start to fly, out-of-body experiences may occur, but consciousness does not leave the body (since it is essentially nonlocal, as we elaborated above). Instead, the shaman's awareness-while being detached from the sensory organs-is focused on and scans the holographic representation of the environment within his/her body since the whole body is the interface, the medium of the "quantum array antennae" of nonlocal correlations. As the Huna and the Shuar tradition puts it: the mental soul (uhane or muisak, respectively) gets the visions from the body soul (unihipili or arutam, respectively) (Winkelman and Baker, 2008; Wesselman, 2008). Authentic shamans are the masters, though not the only ones, of nonlocal realms, since they may remotely sense and perhaps modify the state of a system they are entangled with, and they express their experience in terms and symbols people can understand within their culturally shaped cosmology at the 'perceptual-cognitive' level. They are able to bring information from the nonlocal aspect of the universe (the 'world of things hidden') into the local one (the 'world of things seen') in order to improve the integrity of their community.

Every success of the "coping machinery," such as fame, position, money, or other forms of social acceptance, empowers the ego, unless the individual interprets his or her achievements as gifts from the "outside" and considers the self as a "vessel," a mediator of majestic powers. Identifying too strongly with the agent of the 'perceptual-cognitive' processing (i.e., the ego) suppresses the 'nonlocal-intuitive' way. "It is easier for a camel to go through the eye of a needle, than for a rich man to enter into the Kingdom of God" (Matthew 19: 24). Wisdom traditions usually recommend a humble attitude for approaching the spiritual realm. Without humility its full potency remains hidden beyond the veil. Perhaps there is no need to smash the ego entirely; elimination of ego-inflation might be enough, and what is left should be used in service of the common good. 


\section{Nonlocal Entities}

As stated above, communication with spirits is a key feature of shamanic practice. In the shamanic practice spirits are the source of the healing power and the source of the reintegrative information. According to the model we have presented, spirits appearing in the SSC are real beings, in some sense, and not sheer products of imagination. The proposed duality of knowledge and reality detailed in this essay suggests that they are informative and in some sense autonomous structures of the nonlocal realm. ${ }^{8}$ It may sound mind-boggling, but the concept of their spiritual existence is not in denial with their physical reality.

Contrary to disintegrative mental states, like psychosis or delirium, the spirits of the wellintegrated SSC may convey information existing in the nonlocal realm (or in Ervin Laszlo's words the 'Akashic deep dimension') which may be brought ('in-formed' is Laszlo's term) into 'cognitive-symbolic' processing in a culturallyspecific manner (as angels, djinns, devas, jivas, etc.). It just increases the complexity of the phenomenon that these "nonlocal entities" are indeed "quasi-autonomous" since the belief system of the percipient has a significant influence on their visionary appearance. This essay concludes that shamanic healers have indeed been coming into contact with a spiritual intelligence that appears to antedate space-time as we know it. Spiritual beings are 'nonlocal' entities, and with the help of the body-mind complex they emerge intrapsychically in a SSC from dominions beyond space-time in the universe.

\section{Generalization of Neural Pruning and Shamanic Initiation}

The shamanic state of consciousness involves a profound change of perception which can include visual, auditory, olfactory (smell related), gustatory (taste related) and somatic (bodily) illusions or hallucinations, and synesthesia. The latter is an unusual blending of sensory modalities, for example, sounds may be perceived as images, or colors may be perceived as smells. In a similar manner, 'nonlocal-intuitive' knowledge can also be transformed into sensory perception. An initiated shamanic healer can visualize aura around the sick person and identify an herb with matching aura for treatment, or can hear the "songs" of the healing

${ }^{8}$ Arising from the 'Akashic deep dimension' (a term Ervin Laszlo [in press] has recently adopted).

eISSN 1303-5150 plants and use this embedded information for therapeutic purposes (Beyer, 2011). We suppose that auras and "songs" may appear when synesthesia occurs between the two channels of information processing (i.e., local and nonlocal). It includes conversion of the 'nonlocal-intuitive' information into visual or auditory percepts. This type of aura is probably different from visualized electromagnetic fields surrounding living or unanimated objects, and cannot be photographed using Kirilian methodology. While these mental projections can't be recorded instrumentally, they may convey relevant information for the healer. Usually shamanic initiation (either ritual or spontaneous) is essential to acquire this kind of psychic faculties, and the most important step in becoming a seer is opening one's inner eye.

Shamanic initiation is the most arduous form of the Hero's journey (Walsh, 2007). It involves methods similar to the trance-inducing techniques, but the initiate is usually introduced to them in an extreme manner. Symbolic death and subsequent rebirth is the culminating point of the shamanic 'rite of passage' and represents the means by which the novice will gain his/her visionary skill and healing power. Here we have arrived at our last question: How can shamanic initiation provide the necessary skills?

There is a principle observed in brain development which can be called 'the law of pruning.' It is manifested in successive stages of the maturation of the central nervous system: during critical periods of neural ontogenesis, and before important developmental milestones, there is a strictly programmed, finely patterned, marked reduction in progressively smaller elements of the information processing system of the brain. Due to programmed neuron death, humans are born with significantly fewer nerve cells than they had during intrauterine life. At time of birth the neural potential is diminished by an order of magnitude whilst in the womb. This program is described in the neuro-Darwinian selection model of Gerald Edelman (1987) as neurons competing with each other for survival. During the first years of life, there is a reduction of axon arborization (production of new nerve fibers), which is related to the development of critical periods of perception, communication, and socialization (Squire et al., 2012). In puberty, pruning of synapses establishes neuroaxonal conditions for abstract thinking (Feinstein, 2014), marking the onset of Jean Piaget's 'formal operations' stage (Inhelder and Piaget, 1958). The principle 
plausibly follows that more is not necessarily better for the brain. It shows how at critical points in maturation and immediately prior to developmental leaps, the neuroaxonal system experiences marked reductions in ever smaller scales of its information processing systems. However, this phenomenon is entirely different from random neuronal cell loss observed as resulting from degenerative diseases or intoxicants. In contrast to those degenerative conditions, the pruning processes are strictly programmed and follow certain rules under particular environmental conditions.

There is no reason to believe that the process of pruning ever ceases within a human lifecycle, indicating a possibility that the sprouting of higher cognitive states like SSC, may involve pruning at lower organizational levels within the subcellular matrix, privileging access to nonlocal connections as result of shamanic initiation (or holy life). This is a birthright only few of us can put to use.

\section{Final Remarks}

The 'nonlocal-intuitive' perception of the world deserves rigorous training, as is common in all fields of science and medicine. This training would most likely culminate in shamanic initiation, attaining its highest developmental form. It may take decades to train an indigenous shaman because the 'nonlocal-intuitive' route into the realm of non-ordinary consciousness is seemingly capricious, its denizens are so unpredictable, and our 'perceptual-cognitive' mind is so unprepared, being incapable of distinguishing between what is personal and what is transpersonal. What can be nourished, can be atrophied as well; the latter might have happened in Western civilization and all experience gained over history by the 'nonlocalintuitive' channel has become forgotten knowledge. The resulting imbalance between the two foundations of knowledge has led to a form of "tunnel vision" which ignores or downplays the millennia old shamanic tradition, and which is unable to fully understand entire civilizations, such as pre-Columbian America, even while standing in awe of their phenomenal cultural achievements.

With all these limitations kept in mind, in this essay we are arguing that the current mainstream concept of reality must be expanded before a complete explanation of shamanic practice can be framed. Fully understanding the SSC may require a more sophisticated model of reality than scientific empiricism currently allows.

\section{Acknowledgments}

We thank Jeremy Narby for assistance with the finalization of the manuscript and Michael Winkelman for comments that greatly improved the manuscript. 


\section{References}

Beyer SV. Singing to the Plants: A Guide to Mestizo Shamanism in the Upper Amazon. Albuquerque: University of New Mexico Press, 2011.

Bishop JP. The Anticipatory Corpse: Medicine, Power, and the Care of the Dying (ND Studies in Medical Ethics). Notre Dame: University of Notre Dame Press, 2011.

Bristol M. The psychotropic Banisteriopsis among the Sibundoy of Colombia. Botanical Museum Leaflets, Harvard University 1966; 21: 113-140.

Burnham S. The Art of Intuition. New York: Jeremy P. Tarcher/Penguin, 2011.

Castaneda C. Separate Reality. Further Conversations with Don Juan. New York: Washington Square Press, 1971/1991.

de Araujo DB, Ribeiro S, Cecchi GA, Carvalho FM, Sanchez TA, Pinto JP, de Martinis BS, Crippa JA, Hallak JE and Santos AC. Seeing with the eyes shut: Neural basis of enhanced imagery following Ayahuasca ingestion. Human Brain Mapping 2012; 33: 2550-2560.

DeVos HM, Potgieter JR and Blaauw JH. Physiological and psychological effects of active-alert hypnosis. Psychological Reports 1999; 84: 1123-1126.

Diószegi V. Sámánizmus. Budapest: Terebes Kiadó, 1998.

Edelman G. Neural Darwinism: The Theory of Neuronal Group Selection. New York: Basic Books, 1987.

Eliade M. Shamanism: Archaic Techniques of Ecstasy. New York: Routledge and Kegan Paul, 1972/1951.

Feinstein S. From the Brain to the Classroom: The Encyclopedia of Learning. Westport: Greenwood Press, 2014.

Frecska E. Nonlocality and intuition as the second foundation of knowledge. NeuroQuantology 2012a; 10: 537-546.

Frecska E. The direct-intuitive-nonlocal mind: Another foundation for knowledge? In: E Laszlo and KL Dennis (eds.). The New Science and Spirituality Reader (pp. 9094). Rochester: Inner Traditions, 2012b.

Frecska E, White KD and Luna LE. Effects of the Amazonian psychoactive beverage Ayahuasca on binocular rivalry: interhemispheric switching or interhemispheric fusion? Journal of Psychoactive Drugs 2003; 35: 367-374.

Goodman FD. Ecstatic Trance: New Ritual Body Postures. Holland: Binkey Kok, 2003.

Grof S. Introduction. In: E Laszlo. A New Map of Reality. The Worldview of 21st Century Science. New York: SelectBooks, Inc., in press.

Harner M. The Way of the Shaman. San Francisco: Harper and Row, 1990.

Harris M. Cultural Materialism: The Struggle for a Science of Culture. New York: Random House, 1979.

Hultkrantz A. A definition of shamanism. Temenos 1973; 9: 25-37.

Ingerman $\mathrm{S}$ and Wesselman $\mathrm{H}$. Awakening to the Spirit World: The Shamanic Path of Direct Revelation. Louisville: Sounds True Inc., 2010.

Inhelder B and Piaget J. The Growth of Logical Thinking from Childhood to Adolescence. London: Routledge and Kegan Paul, 1958.

Jilek WG. Altered states of consciousness in North American Indian ceremonials. Ethos 1982; 10: 326-343.

Laszlo E. Science and the Akashic Field: An Integral Theory of Everything. Rochester: Inner Traditions, 2007.

Laszlo E. A New Map of Reality. The Worldview of 21st Century Science. New York: SelectBooks, Inc., in press.

Nagel T. "What is it like to be a bat?" The Philosophical Review 1974, 83: 435-450.
Narby J and Huxley F (eds.). Shamans Through Time: 500 Years on the Path to Knowledge. New York: Jeremy Tarcher/Penguin, 2001.

Neher A. Auditory driving observed with scalp electrodes in normal subjects. Electroencephalography and clinical neurophysiology 1961; 13: 449-451.

Neher A. A physiological explanation of unusual behavior involving drums. Human Biology 1962; 34: 151-160.

Peracchia C. Gap Junctions: Molecular Basis of Cell Communication in Health and Disease. New York: Academic Press, 2000.

Plotinus [O'Brien E]. The Essential Plotinus. Representative Treatises from the Enneads. Indianapolis: Hackett Publishing Company, Inc., 1964.

Prince R. Can the EEG be used in the study of possession states? In: R Prince (ed.), Trance and Possession States (pp. 121-137). Montreal: RM Bucke Memorial Society, 1968.

Rosenblum B and Kuttner F. Quantum Enigma: Physics Encounters Consciousness. Oxford: Oxford University Press, 2011.

Rouget G. Music and Trance: A Theory of the Relations between Music and Possession. Chicago: University of Chicago Press, 1985.

Sarfatti J. Super Cosmos. Bloomington: Author House Publishing, 2005.

Squire L, Berg D, Bloom FE, du Lac S, Ghosh A, Squire LR, Spitzer NC, McConnell SK, Roberts JL, and Zigmond MJ (eds.). Fundamental Neuroscience, Fourth Edition. New York: Academic Press, 2012.

Stevens J and Stevens LS. Secrets of Shamanism: Tapping the Spirit Power within You. New York: Avon, 2004.

Symmons C and Morris R. Drumming at seven $\mathrm{Hz}$ and automated Ganzfeld performance. Parapsychological Association 40th Annual Convention: Proceedings of Presented Papers 1997; 441-454.

Vitebsky P. The Shaman. Voyages of the Soul, Trance, Ecstasy and Healing from Siberia to the Amazon. Boston: Little, Brown and Company, 1995.

Viveiros de Castro E. Cosmological deixies and Amerindian perspectivism. Journal of the Royal Anthropological Institute 1998; 4: 469-488.

Walsh R. The World of Shamanism: New Views of an Ancient Tradition. Woodbury: Llewellyn Publications, 2007.

Wesselman H. Hawaiian perspectives on the matrix of the soul. The Journal of Shamanic Practice 2008; 1: 21-25.

Wesselman H. The Bowl of Light: Ancestral Wisdom from a Hawaiian Shaman. Boulder: Sounds True, 2011.

Winkelman M. Shamanism: A Biopsychosocial Paradigm of Consciousness and Healing. Santa Barbara: Praeger, 2010.

Winkelman M and Baker JR. Supernatural as Natural: A Biocultural Approach to Religion. Upper Saddle River: Prentice Hall, 2008. 